\title{
Predation and Competition
} Differentially Affect the Interactions and Trophic Niches of a Neotropical Amphibian Guild

\section{OPEN ACCESS}

Edited by:

Deseada Parejo,

Universidad de Extremadura, Spain

Reviewed by: Wei Chen,

Mianyang Normal University, China Perri Eason, University of Louisville, United States

${ }^{*}$ Correspondence: Ivan Gomez-Mestre igmestre@ebd.csic.es

Specialty section: This article was submitted to Behavioral and Evolutionary Ecology, a section of the journal

Frontiers in Ecology and Evolution

Received: 09 September 2017 Accepted: 08 March 2018 Published: 23 March 2018

Citation:

Arribas R, Touchon JC and Gomez-Mestre I (2018) Predation and Competition Differentially Affect the Interactions and Trophic Niches of a Neotropical Amphibian Guild. Front. Ecol. Evol. 6:28. doi: 10.3389/fevo.2018.00028

\author{
Rosa Arribas ${ }^{1}$, Justin C. Touchon ${ }^{2,3}$ and Ivan Gomez-Mestre ${ }^{1 *}$ \\ ${ }^{1}$ Ecology, Evolution, and Development Group, Department of Wetland Ecology, Doñana Biological Station, CSIC, Seville, \\ Spain, ${ }^{2}$ Smithsonian Tropical Research Institute, Panama City, Panama, ${ }^{3}$ Department of Biology, Vassar College, \\ Poughkeepsie, NY, United States
}

Competition and predation alter individual traits of organisms, and these effects can scale-up to have consequences on community structure and dynamics. The relative importance of competition and predation will depend largely on the local assemblage of species, the type of predators, or the degree of niche segregation. We experimentally investigated the interplay of competition and predation on the structure and trophic level (measured via stable isotope analysis) of a seven-species Neotropical freshwater guild using a mesocosm approach in central Panama. We tested the effect of two types of predators (dragonfly nymphs or adult water bugs) in combination with the presence/absence of a common competitor, the red-eyed treefrog (Agalychnis callidryas), on four core species of tadpoles. We also distinguished between consumptive and non-consumptive effects of each type of predator by presenting them to tadpoles caged or freely roaming. Dragonfly larvae were more efficient predators than water bugs, but these effects were not uniform for all tadpole species. All amphibian species grew bigger when raised in the presence of an uncaged dragonfly nymph, presumably due to reduced competition through thinning, but tadpoles were smaller when exposed to caged dragonfly nymphs indicating the existence of non-consumptive predator effects as well. Predator presence also altered the relative trophic position of the different amphibian species, causing some tadpole species to increase and others to decrease their trophic status. Despite the presumed ecological similarity of tadpole species in the guild, the interplay of competition and predation had varying effects on the trophic status of nearly every species. Our results indicate that community composition can greatly affect the trophic level of larval amphibians, and that predation may have a greater role than competition in structuring Neotropical larval amphibian guilds.

Keywords: competition, predation, growth rate, community ecology, trophic niche, trophic plasticity, stable isotopes, amphibian larvae

\section{INTRODUCTION}

The structure and dynamics of ecological communities is ultimately determined by just four basic processes: selection, drift, speciation, and dispersal (Vellend, 2010; Kozak and Wiens, 2012). Species can become incorporated into communities by speciation or dispersal, whereas drift and selection are responsible for fluctuations in the relative abundance of species in a community. Stochastic and 
deterministic factors further influence temporal and spatial species turnover that in turn determine which species interact at any given time and their relative abundances (Legendre et al., 2005), creating broad-scale variation in community composition (Berg and Bengtsson, 2007; Soininen, 2010). On top of these factors, ecological interactions such as predation and competition are decisive in structuring community composition. Predation and competition directly affect trophic relationships among species, which are key in dictating species coexistence (Pimm, 1982; Morlon et al., 2014). However, while the trophic status of species and communities is recognized as crucial to understanding energy flow, nutrient cycling, species coexistence and community assembly (Pimm, 1982; Pascual and Dunne, 2005), we have relatively little information on how different members of a guild might alter their feeding niche when subjected to predation and competition. Therefore, direct assessments of trophic interactions are needed to better understand community composition and shed light on the complex relationships between competition and predation that arise as different species are involved (Arribas et al., 2014, 2015).

Determining trophic relationships among interacting species is far from trivial. Although community ecology has often viewed species as fixed entities that interact in easily predictable ways (Ackerly, 2003), the outcome of trophic interactions is highly context dependent because a set of interacting species may produce different community structures and dynamics under slightly different scenarios. For instance, reduced food availability can force previously trophically distinct species to overlap, thereby intensifying competitive interactions (GómezCampos et al., 2011). However, competition can also have the opposite effect, increasing niche partitioning through ecological diversification (Svanbäck and Bolnick, 2007). Predators further complicate understanding trophic relationships, since they can relax or reverse effects of competition (Gurevitch et al., 2000; Relyea, 2000). Lastly, alterations in ecological interactions are not exclusively mediated by density-dependent effects but also by non-consumptive effects (Werner and Peacor, 2003; Schmitz et al., 2004). This is because organisms often show a high degree of plasticity in their behavior, morphology, and lifehistory traits in response to competitors and predators (Werner and Peacor, 2003; Prasad and Snyder, 2006; Zanette et al., 2011). Plastic changes in the phenotype of interacting species may alter ecological interactions (Schmitz et al., 2004), for instance reducing the strength of competition (Relyea, 2000; Mowles et al., 2011). The reverse can also occur and competition can change the strength of trait-mediated indirect effects (Bolnick and Preisser, 2005).

Aquatic communities are amenable to experimental approaches because they can be reasonably well replicated in outdoor mesocosms to achieve a good combination of realism and experimental control (Wilbur, 1997; Nystrom et al., 2001). Larval amphibians in particular make good model organisms for studying ecological interactions. Competition and predation have been extensively studied in temperate amphibian guilds (Morin, 1983; Wilbur, 1997), whereas tropical amphibian guilds have been far less studied, despite their greater diversity and hence increased potential for complex ecological interactions
(Azevedo-Ramos et al., 1999; Hero et al., 2001). Moreover, little research has examined the combined effects of predation and competition on tropical anuran guilds (but see Gonzalez et al., 2011), and studies of the trophic ecology of tropical amphibians is similarly scarce (Whiles et al., 2006; Verburg et al., 2007; but see Costa and Vonesh, 2013b). Most tadpoles are viewed simply as herbivorous grazers or filter feeders (Alford, 1999); the historical assumption has been that the vast majority of tadpoles occupy a similar feeding niche (Altig et al., 2007). However, a wide variety of mouthpart specializations and behaviors exist, indicating the potential for much more complex trophic niches (Altig et al., 2007). Furthermore, our limited empirical knowledge of what tadpoles eat may not actually reflect what they digest and assimilate (Altig et al., 2007) and when the trophic niches of individual species have been examined over time or space, studies have found substantial plasticity in diet breadth and source material (Whiles et al., 2010; Schriever and Williams, 2013). Importantly, most of our perception about niche partitioning in tropical amphibians has been inferred from mouthpart morphology or behavior of a very limited number of species and thus may not accurately reflect the true diversity of roles potentially played by anuran larvae (Alford, 1999; Altig et al., 2007; reviewed in Wells, 2007).

We studied the consequences of consumptive and nonconsumptive predator effects and competition on the trophic level, size, and survival of individuals in a tropical amphibian guild. Utilizing an amphibian guild of four core species, we conducted a mesocosm experiment manipulating the presence of a large tadpole with a high potential for competition (Agalychnis callidryas; Gonzalez et al., 2011), and the presence of either caged or free-roaming predators (either water bugs or dragonfly nymphs). We used stable isotopes to assess how the trophic status of each amphibian species was altered in response to predation and competition (Post, 2002; Caut et al., 2013). Stable isotopes reveal long-term assimilation of resources instead of a snapshot of the resources ingested, such as gut content analyses or behavioral tests might provide. Stable carbon isotope ratios $\left(\delta^{13} \mathrm{C}\right)$ identify major sources of energy, whereas stable nitrogen isotope ratios $\left(\delta^{15} \mathrm{~N}\right)$ can be used to estimate trophic position within a food web since consumers are usually enriched by $3-4 \%$ in $\delta^{15} \mathrm{~N}$ relative to their food sources (DeNiro and Epstein, 1981; Layman et al., 2012), and about $2 \%$ in tropical aquatic systems (Whiles et al., 2006). Therefore, changes in isotopic ratios reflect variation in the resources an organism consumes (nutrient flow, Layman et al., 2012).

We hypothesized that all tadpole species within the guild would experience strong competition from A. callidryas, whose tadpole grows bigger than the other species and feeds mostly by filtering algae from the water column (Costa and Vonesh, 2013a). We also expected that tadpoles co-habiting with $A$. callidryas would shift to feeding on periphyton or decomposing leaf litter at the pond bottom rather than from algae in the water column to reduce competition. This would result in altered carbon sources and in lower $\delta^{15} \mathrm{~N}$ values, as periphyton and leaf litter are considered low quality food and tend to show lower $\delta^{15} \mathrm{~N}$ than algae (see Schriever and Williams, 2013). Alternatively, strong competition causing low food availability could increase 
consumer's $\delta^{15} \mathrm{~N}$ due to an increase of catabolism of their tissues (Bowes et al., 2014). Values of $\delta^{13} \mathrm{C}$ would also be affected as algae and detritus have different isotopic signals and are variable depending on the environment.

We predicted that predators would reduce competition from A. callidryas, benefiting smaller tadpole species and shifting the carbon source of survivors. Free roaming predators were expected to exert direct consumptive effects, reducing competition from $A$. callidryas, thereby increasing the body size of survivors and increasing the availability of higher trophic resources (i.e., increasing $\delta^{15} \mathrm{~N}$ ).

The two predators were chosen for their different niches and thus potential for different effects on tadpole trophic ecology. Water bugs generally remain near the top of the water column; we therefore expected them to cause tadpoles to feed mostly on leaf litter or periphyton in the bottom of the mesocosms, thereby showing a decrease in $\delta^{15} \mathrm{~N}$. Dragonfly nymphs are more likely to remain in the leaf litter or on the walls of the mesocosms, potentially causing tadpoles to filter more algae from the water column, thereby increasing the trophic status of survivors (higher $\left.\delta^{15} \mathrm{~N}\right)$. Lastly, we also hypothesized that indirect trait-mediated effects of both predators would decrease tadpole growth through reduction of foraging activity, and constrain them to a lower trophic status (lower $\delta^{15} \mathrm{~N}$ ) as tadpoles would tend to spend longer times seeking refuge in the bottom of the tank.

\section{MATERIALS AND METHODS}

\section{Study System}

The study was conducted at the Smithsonian Tropical Research Institute in Gamboa, Panama $\left(9^{\circ} 7^{\prime} 17^{\prime \prime} \mathrm{N}, 79^{\circ} 42^{\prime} 11^{\prime \prime} \mathrm{W}\right)$ between 13 June 2012 and 13 July 2012. We included five tadpole species in this experiment that are locally abundant at the study site and that co-occur and breed throughout the rainy season (MayDecember at our study site). The red-eyed treefrog Agalychnis callidryas lays arboreal clutches that hatch in 6-7 days if left undisturbed (Gomez-Mestre et al., 2008). Tadpoles of this species feed primarily on phytoplankton or periphyton (i.e., a mixture of algae, bacteria and detritus attached to submerged surfaces) while suspended in the mid-water column (Warkentin, 1999; Wells, 2007). The pantless treefrog Dendropsophus ebraccatus lays eggs terrestrially and in water depending on the shade above the pond (Touchon and Warkentin, 2008) and they hatch in ca. 3.5 days. Tadpoles are benthic grazers that feed on filamentous algae and periphyton along the water column (Costa and Vonesh, 2013a). The small-headed treefrog Dendropsophus microcephalus and the red-snouted treefrog Scinax ruber lay clutches in the water and the eggs hatch in 2-3 days. The specific diets of the tadpoles of D. microcephalus and $S$. ruber remain unknown, although they are presumed to be macrophagous herbivores (Wassersug, 1980). Lastly, the Tungara frog Engystomops pustulosus generates a floating foam nest (Ryan, 1985) that protects the fertilized eggs until hatching after 3-4 days. Tungara tadpoles (E. pustulosus) are known to be mainly filter feeders (Rand, 1983). The predators used for this study were aeshnid dragonfly larvae (Family Aeshnidae) and giant water bugs Belostoma sp. (Family Belostomatidae), both of which are commonly found in the ponds where frogs usually breed in Gamboa (Touchon and Vonesh, 2016). These two aquatic insects generally differ in their position in the water column (dragonflies in the leaf litter or on submerged vegetation whereas water bugs are more common at the top of the water column).

\section{Experimental Design}

The experimental procedures used in this study were approved by the Smithsonian Tropical Research Institute Bioethics Committee (permits STRI IACUC \# 20110801-2014-01). To examine the interactions between competition (with $A$. callidryas) and predation on growth and survival of the larval amphibian community, we conducted a 2 x 5 factorial mesocosm experiment where we crossed presence of $A$. callidryas with one of five predator treatments: a no predator control (NP hereafter), either uncaged dragonfly larvae or adult water bugs (D-uncaged and WB-uncaged, respectively) or caged dragonfly larvae or adult water bugs (D-cage and WB-cage, respectively). Each treatment combination was replicated eight times for a total of 80 experimental tanks distributed in eight fully randomized spatial blocks (Figure 1). This design allowed us to distinguish the competitive effect of $A$. callidryas and the consumptive and non-consumptive effects of predators (freely roaming or caged). Each mesocosm began with 10 tadpoles per species and therefore mesocosms with $A$. callidryas started with 50 tadpoles in total, whereas mesocosms lacking $A$. callidryas started with 40 tadpoles. This additive design provides a direct test for interspecific competition (Underwood, 1986; Gomez-Mestre and Tejedo, 2002).

Our experimental mesocosms were arranged in an open field next to secondary forest and consisted of $400 \mathrm{~L}$ round plastic tanks $(0.75 \mathrm{~m}$ diameter and $0.8 \mathrm{~m}$ high) with screened drain holes at a height of $0.75 \mathrm{~m}$. One month before the start of the experiment we added an even mixture of loosely packed dry soil and leaf litter (ca. $7,000 \mathrm{~cm}^{3}$ ) to each tank and filled them approximately one third full with collected rain water and aged tap water. The soil used was collected during the dry season from a dried pond that fills only during the wet season ("Bridge Pond" from Touchon and Vonesh, 2016). All amphibian and predator species are known to occur in this pond. We covered the tanks with window screen to prevent colonization by unwanted organisms and allowed rainwater to fill the tanks at the beginning of the experiment. This process allowed a natural food base for the aquatic community to develop, thereby mimicking the conditions of many ponds in the area. To provide spatial complexity, we added three plastic pots containing plants transplanted from Bridge Pond. Each pot contained four individual plants. The plants were completely submerged beneath the surface of the water but grew and were alive throughout the entire experiment. Since our tanks contained a mixture of vegetation and soil and had been allowed to fill naturally, they contained a substantial amount of visible periphyton at the start of the experiment. No supplementary food was added to mesocosms during the experiment and tadpoles consumed only what had developed naturally.

Each tank contained one predator cage made of a fine mesh that was suspended at the top of the water column on a side 


\section{Experimental setup}

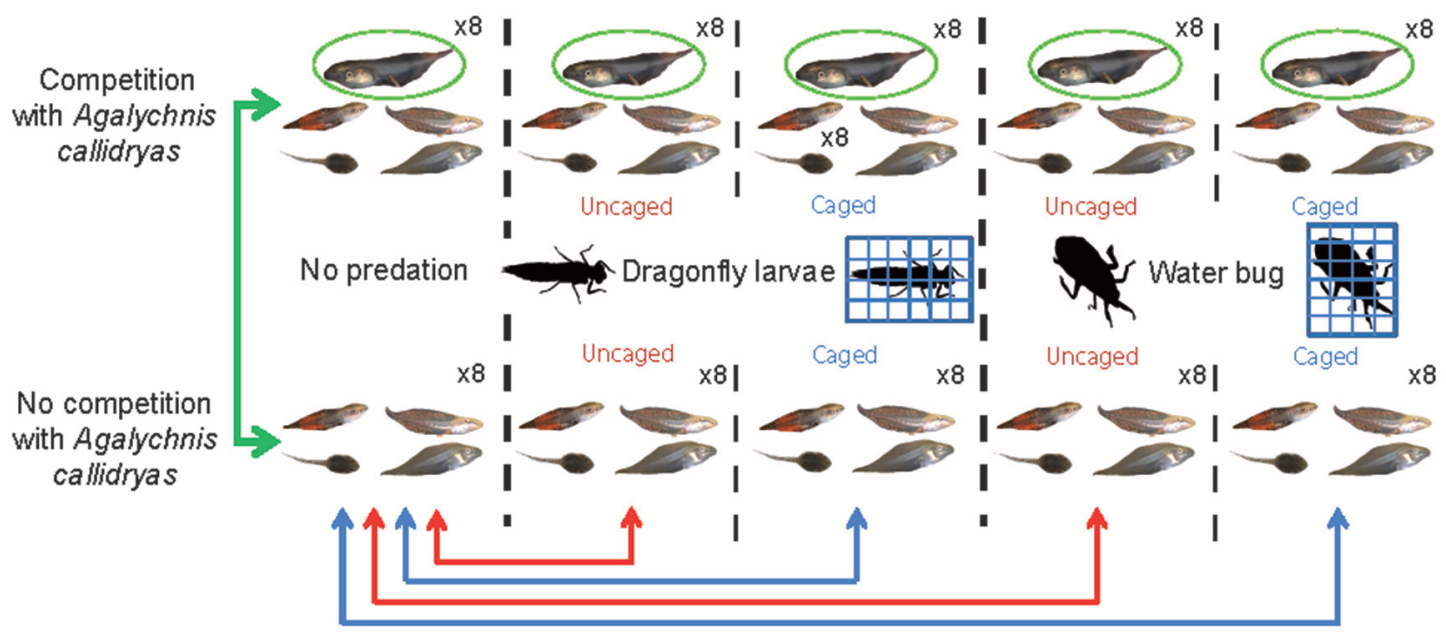

Test for:
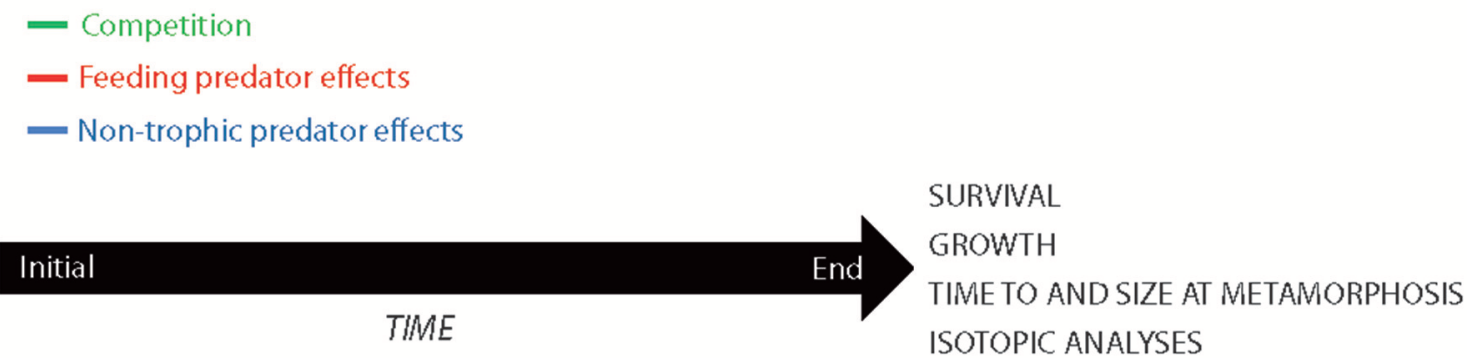

FIGURE 1 | Configuration of the experimental setup used to examine the relative effects of competition and predation on a tropical anuran guild. We manipulated the presence/absence of a potential competitor (Agalychnis callidryas) on four other amphibian species (marked in green). We also tested the effect of two types of predators (dragonfly larvae and water bug) on amphibian larvae. We presented the predators either free (uncaged; marked in blue) or caged (marked in red) to test for consumptive and non-consumptive effects of these predators. The experiment lasted 4 weeks and at the end we recorded survival and growth of amphibians, time to and size at metamorphosis, and took tissue samples for isotopic analysis. All tadpole photos by JT.

of each tank. All cages contained a stick for predators to perch on. Identical empty cages were included in tanks lacking a caged predator treatment. Dragonfly larvae and adult water bugs were collected from ponds in the area and haphazardly assigned to either free or caged predator treatment. We introduced one predator in each predator cage or left them empty according to the assigned treatment. The average body length of dragonflies was $18.2 \pm 0.27 \mathrm{~mm}$ (mean \pm SE here and throughout, $n=32$ ) and that of water bugs was $40.38 \pm 0.37 \mathrm{~mm}(n=32)$. Caged predators were fed every other day with two tadpoles of any one of the five amphibian species included in the experiment, selected on a rotating basis, to ensure consistent alarm cues (Peacor, 2006). We replaced predators that died as necessary.

To ensure that all eggs would hatch at approximately the same time, we collected clutches of A. callidyras first, then collected $D$. ebraccatus 1 day later, and clutches of D. microcephalus, $S$. ruber, and E. pustulosus 1 day later (i.e., 2 days after collecting A. callidyras). This allowed all tadpoles to be essentially the same age post-hatching (2 days) at the start of the experiment. All tadpoles and predators were dorsally photographed just before introducing them into the mesocosms. From the first day of the experiment we checked the tanks daily and from the day we found the first metamorph we checked the tanks for metamorphs twice a day. The experiment lasted for 4 weeks and we removed the remaining tadpoles and predators with dip nets between 10 and 13 July. Immediately upon removal, we individually photographed tadpoles and recorded body mass. All photographs included a ruler for scaling the image and to obtain measurements of predators' body length and tadpoles' body length and total length (TL, body plus tail). For individuals that had already metamorphosed, we recorded snout-vent length (SVL). Photographs were measured using the program ImageJ 1.46r (Rasband, 2012). Initial total length was $11.8 \pm 0.01 \mathrm{~mm}$ for A. callidryas, $6.5 \pm 0.004 \mathrm{~mm}$ for $D$. ebraccatus, $5.4 \pm 0.003 \mathrm{~mm}$ for $D$. microcephalus, $6.1 \pm 0.004 \mathrm{~mm}$ for $S$. ruber and $8.3 \pm 0.009$ for E. pustulosus. There were no differences in initial size within species across treatments (all $p>0.12$ ). At the end of the experiment, all individuals not used for stable isotope analyses were released at the site of collection. 


\section{Stable Isotopes Analysis}

We performed analyses of stable isotopes on one individual per species per tank when available, from 6 of the experimental blocks. We obtained isotopic data from a total of 178 tadpoles (A. callidryas $=24$ tadpoles; $D$. ebraccatus $=52$ tadpoles; $D$. microcephalus: 54 tadpoles; and $S$. ruber $=48$ tadpoles) except $E$. pustulosus $(n=47)$, where most individuals had metamorphosed by the end of the experiment. The isotopic signature does not differ between tadpoles and newly metamorphosed juveniles, because amphibians do not feed during metamorphosis (Arribas et al., 2015). We euthanized individuals by immersion in MS-222, dissected tail muscle or leg muscle as appropriate, and then froze samples at $-20^{\circ} \mathrm{C}$ until processing. We also sampled possible food sources (i.e., phytoplankton, periphyton, zooplankton, sediment and plants) and processed them following the procedures in Arribas et al. (2015). All samples were ovendried at $50^{\circ} \mathrm{C}$ to constant dry weight and ground to a fine and homogeneous powder with mortar and pestle. Weighed samples $(0.3 \pm 0.003 \mathrm{mg}$ per sample) were processed at the Stable Isotopes Laboratory at Doñana Biological Station. Samples were combusted at $1,020^{\circ} \mathrm{C}$ using a continuous flow isotoperatio mass spectrometry system by means of Flash HT Plus elemental analyzer coupled to a Delta-V Advantage isotope ratio mass spectrometer via a CONFLO IV interface (Thermo Fisher Scientific, Bremen, Germany). Stable isotope ratios are expressed in the standard $\delta$-notation (\%o) relative to Vienna Pee Dee Belemnite $\left(\delta^{13} \mathrm{C}\right)$ and atmospheric N2 $\left(\delta^{15} \mathrm{~N}\right)$, using the equation $\delta^{13} \mathrm{C}$ or $\delta^{15} \mathrm{~N}=\left(\left(\mathrm{R}_{\text {sample }} / \mathrm{R}_{\text {standard }}\right)-1\right) \times 1000$, where $\mathrm{R}$ is ${ }^{13} \mathrm{C}:{ }^{12} \mathrm{C}$ or ${ }^{15} \mathrm{~N}:{ }^{14} \mathrm{~N}$. Laboratory standards run every nine samples, and calibrated with international standards, indicated measurement errors of \pm 0.1 and $\pm 0.2 \%$ or for $\delta^{13} \mathrm{C}$ and $\delta^{15} \mathrm{~N}$, respectively. Amphibian $\delta^{13} \mathrm{C}$ values were normalized to account for lipid variation in $\delta^{13} \mathrm{C}$ (mean $\mathrm{C}: \mathrm{N}=3.41$ ) following the recommended equations in Caut et al. (2013): $\delta^{13} \mathrm{C}$ normalized $=\delta^{13} \mathrm{C}$ untreated $-1.11+0.37 \mathrm{C}: \mathrm{N}$.

\section{Statistical Analyses}

We conducted all statistical analysis using R 2.15.3 (R Core Team, 2013). We used generalized linear mixed models (glmer function in package lme4) to analyze effects of the different treatments on (1) survival, (2) size (total length, TL), and (3) diet of amphibians. We first performed an overall model including the three-way interaction among competition with $A$. callidryas (two levels, presence/absence), risk of predation (all five predator treatments), and amphibian species (four core species). Experimental block was included as a random factor for survival and diet analyses. Block and tank within block were included as random factors for size analyses. In all models described below, we used likelihood ratio tests to evaluate the significance of each predictor. We analyzed tadpole survival with generalized linear mixed models fitting a binomial error distribution using a logit link function, and analyzed tadpole size and diet (stable isotope data) fitting a Gaussian error distribution. We assessed model fits using qq-plots and ensured that models were not overdispersed. When appropriate, assumptions of normality and homoscedascity of errors were assessed by means of ShapiroWilks and Bartlett tests respectively.
Since we found significant two- and three-way interactions in the overall model (see section Results), we conducted several subsequent analyses to tease apart the effects of competition from predation. First, we evaluated the competitive effect of $A$. callidryas in the absence of predators. Second, in tanks containing A. callidryas (i.e., the complete amphibian guild) we looked for evidence of non-consumptive effects of caged predators (considering only control, WB-cage, and D-cage treatments) and consumptive effects of uncaged predators (considering only control, WB-uncaged and D-uncaged treatments). Third, in the event of a significant interaction between predator treatment and amphibian species, we performed contrast analyses to examine differences between types of predators (dragonfly vs. water bugs). Given that these multiple comparisons were at times not orthogonal, we corrected the $P$-values to minimize the false discovery rate (FDR; Benjamini and Hochberg, 1995). The FDR is a simple and powerful method for controlling type I error when multiple comparisons are carried out (Verhoeven et al., 2005).

We tested if the initial length of tadpoles explained differential survival among species, using tank means of initial total length for each species. We found no effect of initial body length on survival and the covariate was removed from the final model $\left(\chi^{2}=1.47 ; P=0.22\right)$. We analyzed each species size using measurements of tadpoles' total length (final TL, in $\mathrm{mm}$ ), from the photographs taken at the end of the experiment, and including initial body length (mean per tank and per species) as a covariate in the model to control for initial differences in body size.

In testing for differences in isotopic signatures, we first tested for an association between tadpole size (TL) and isotopic values for each species using linear regressions. We then used generalized linear mixed models to test for the effects of predator presence, competition, and species on isotopic value $\left(\delta^{13} \mathrm{C}\right.$ or $\left.\delta^{15} \mathrm{~N}\right)$. Lastly, we performed the above analyses on each species separately to test the effect of competition from A. callidryas with respect to the presence of free and caged predators.

We occasionally found undesired dragonflies in our mesocosms at the end of the experiment, presumably introduced with the sediment or leaf litter. Based on external morphology of the nymphs, these dragonflies were from the family Gomphidae and are not reported to feed on tadpoles (known diets include midge larvae and oligochaete worms; Mahato and Johnson, 1991; Alzmann et al., 1999). Gomphidae dragonfly nymphs are bottom dwellers with relatively poor eyesight compared with more active predatory species like Anax (Corbet, 1962). Gomphid nymphs were relatively evenly distributed throughout the experiment, occurring in 17 of our 80 mesocosms, and never in more than three mesocosms from any given treatment. When they did occur, they were generally sparse (mean number of individuals per mesocosm: 3.6, mode per mesocosm: 1). However, we included the number of unwanted dragonflies as a covariate in the analyses of tadpole survival to check if they had an effect on survival, which was not significant $\left(\chi^{2}=2.257 ; P=0.133\right)$ and we thus removed it from the model. 


\section{RESULTS}

Statistical results for the effects of competition and either caged or uncaged predators on amphibian survival, size and stable isotopes are shown in Table 1. Magnitude and effect sizes for effects of competition and predation on survival, size, and stable isotopes are shown in Table 2.

\section{Survival}

In the overall model, survival was not affected by the three-way interaction between competition, predation and tadpole species $\left(\chi^{2}=5.32 ; P=0.95\right)$ but was strongly affected by predator treatment $\left(\chi^{2}=262.93 ; P<0.001\right)$, tadpole species $\left(\chi^{2}=198.24\right.$; $P<0.001)$, and the interaction between them $\left(\chi^{2}=189.65 ; P<\right.$ $0.001)$. Neither the "competition $\times$ species" interaction nor the "competition $\times$ predation" interaction was significant (both $P>$ $0.1)$.

In the absence of predators, competition from A. callidryas did not significantly affect survival of the other amphibian species (Tables 1, 2). Both free water bugs and free dragonfly larvae, however, greatly reduced tadpole survival. Nevertheless, not all tadpole species were equally prone to predation, as noted by the significant "predator $\times$ species" interaction (Figure 2, Table 1). Dragonfly predation varied greatly among amphibian species: $E$. pustulosus experienced the greatest mortality (94\%), followed by A. callidryas (91\%), and S. ruber (86\%), whereas D. ebraccatus and D. microcephalus were less impacted (60 and $49 \%$ mortality, respectively; see Appendix 1 Table A1 in Supplementary Material for mean $\pm \mathrm{SE} \%$ survival in the different treatments). Water bugs also negatively impacted tadpole survival, although their effect was less marked than that of dragonflies; the most affected species was E. pustulosus (80\%), followed by S. ruber (51\%), D. ebraccatus (50\%), and D. microcephalus (36\%) whereas the least affected species was A. callidryas (24\%).

Caged predators did not significantly affect amphibian survival. Although species survival varied overall (Figure 2), survival was unaffected by the presence of caged dragonflies or water bugs (Table 1 and Appendices 1, 2 in Supplementary Material).

\section{Size}

The three-way interaction between competition, predation and tadpole species was highly significant for tadpole size (final total length in $\left.\mathrm{mm}[\mathrm{TL}]: \chi^{2}=30.27 ; P=0.00019\right)$. We excluded $E$. pustulosus because most individuals had already metamorphosed and their size was not comparable to the other species, which were still tadpoles.

In the absence of predation, the largest tadpoles at the end of the experiment were A. callidryas, followed by D. microcephalus and S. ruber. Mean size of each species after four weeks is given in Appendix 1 Table A1 in Supplementary Material. In this predator-free scenario, the presence of $A$. callidryas significantly affected growth of the species in different ways (Table 1, competition* species interaction with $P<0.001$ ). Only $D$. ebraccatus suffered from competition from A. callidryas, experiencing decreased growth and overall reduced survival in its presence (Figures 2,3). The effect of predation on growth was nevertheless stronger than the effect of competition, as indicated by their effect sizes (Table 2).

Uncaged predators had a significant effect on tadpole size that varied across species and predators (predation*species interaction with $P<0.001$; Figure 4 and Table 1). In general, the two predators exerted opposing effects, with free dragonflies increasing size of all species, whereas free water bugs reduced size of all species. For example, D. ebraccatus experienced an $18.83 \%$ size increase in the presence of uncaged dragonflies whereas uncaged water bugs caused a decrease in size of 3.57\% (compared to predator-free controls). When analyzing each species separately (Appendix 2 in Supplementary Material) we observed that the effect of uncaged dragonflies was highly significant on the size of $S$. ruber $(z=2.45, P=0.04)$ and marginally significant on the size of $D$. ebraccatus $(\mathrm{z}=2.01, P=$ 0.06 ). Lastly, predator effects were not uniform across amphibian species, as E. pustulosus experienced reduced total length (SVL), weight, and leg length in the presence of uncaged dragonflies (all $P<0.003$ ). Caged predators also had a significant effect on tadpole size that was different depending on the species (Figure 4 and Table 1, significant predation*species interaction). This effect was due to caged dragonflies, which considerably decreased size of tadpoles $(z=-2.59, P=0.02)$ and the SVL of E. pustulosus metamorphs $(z=-2.68, P=0.02)$. When looking at species individually (Appendix 2 in Supplementary Material), we observed that caged dragonflies had a significant effect on the size of $D$. microcephalus $(z=-2.56, P=0.03)$ and a marginal effect on A. callidryas $(z=-2.39, P=0.051)$ and $S$. ruber $(z=$ $-1.89, P=0.09)$. Size in the presence of caged water bugs did not differ from the control in any prey species $(z=-0.42, P=0.9)$.

\section{Diet}

The only significant predictor for $\delta^{13} \mathrm{C}$ isotopic values in the overall model was tadpole species $\left(\chi^{2}=101.04 ; P<0.001\right)$. For $\delta^{15} \mathrm{~N}$ values, however, the three-way interaction between competition, predation and tadpole species was significant $\left(\chi^{2}\right.$ $=22.65 ; P=0.031)$. This "competition $\times$ predator $\times$ species" interaction on $\delta^{15} \mathrm{~N}$ indicates that the effect of competition on the trophic status of amphibians was dependent upon the presence of predators and was dissimilar across species. For example, in the absence of predators A. callidryas did not have an effect on $\delta^{15} \mathrm{~N}$ of $D$. microcephalus, but did induce a significant decrease in $\delta^{15} \mathrm{~N}$ when uncaged dragonflies were also present (Table 3). In general, the sole effect of competition on the isotopic signature of tadpoles was negligible except for D. ebraccatus, who greatly reduced $\delta^{15} \mathrm{~N}$ in the presence of $A$. callidryas (Table 2).

Total body length (TL) of all species (except E. pustulosus) was positively related to $\delta^{13} \mathrm{C}$ (Pearson's $r=0.31, P<0.001$ ) but no correlation was observed between size and $\delta^{15} \mathrm{~N}$. In particular, D. ebraccatus had relatively small tadpoles but fed at the highest trophic level (highest $\delta^{15} \mathrm{~N}$ values).

Uncaged predators did not significantly affect the values of $\delta^{13} \mathrm{C}$, but had varying effects on $\delta^{15} \mathrm{~N}$ values (Figure 5 and Table 1). Uncaged dragonflies decreased $\delta^{15} \mathrm{~N}$ of $D$. microcephalus, S. ruber and A. callidryas (by 3.9, 18.6, and $16.4 \%$, respectively), but slightly increased $\delta^{15} \mathrm{~N}$ of 
TABLE 1 | Community responses (for survival, final total length and stable isotopes) to competition and predation.

\begin{tabular}{|c|c|c|c|c|c|c|c|c|}
\hline \multirow[t]{2}{*}{ Statistical Models } & \multicolumn{2}{|c|}{ Survival } & \multicolumn{2}{|c|}{ Final total length } & \multicolumn{2}{|c|}{$\delta^{13} \mathrm{C}$} & \multicolumn{2}{|c|}{$\delta^{15} \mathrm{~N}$} \\
\hline & $x^{2}$ & $p$ & $x^{2}$ & $p$ & $x^{2}$ & $p$ & $x^{2}$ & $p$ \\
\hline \multicolumn{9}{|l|}{ COMPETITION } \\
\hline Competition*Species & 0.5814 & 0.9 & 18.355 & $<0.001$ & 2.669 & 0.445 & 2.35 & 0.5 \\
\hline Competition & 0.7074 & 0.4 & 0.011 & 0.917 & 2.303 & 0.129 & 1.473 & 0.225 \\
\hline Species & 29.024 & $<0.001$ & 344.6 & $<0.001$ & 14.666 & 0.002 & 34.535 & $<0.001$ \\
\hline \multicolumn{9}{|c|}{ PREDATION: FREE PREDATORS } \\
\hline Predation`Species & 72.867 & $<0.001$ & 16.5 & $<0.001$ & 4.803 & 0.778 & 19.525 & 0.012 \\
\hline Predation & 204.09 & $<0.001$ & 0.592 & 0.44 & 5.083 & $0.078^{\star}$ & 9.976 & 0.007 \\
\hline Species & 84.468 & $<0.001$ & 383.3 & $<0.001$ & 34.283 & $<0.001$ & 80.386 & $<0.001$ \\
\hline \multicolumn{9}{|c|}{ PREDATION: CAGED PREDATORS } \\
\hline Predation*Species & 8.994 & 0.343 & 14.626 & 0.002 & 14.734 & $0.064^{*}$ & 14.9 & $0.06^{*}$ \\
\hline Predation & 5.074 & $0.079^{*}$ & 5.59 & 0.018 & 1.45 & 0.484 & 8.248 & 0.016 \\
\hline Species & 83.495 & $<0.001$ & 407.08 & $<0.001$ & 35.515 & $<0.001$ & 98.83 & $<0.001$ \\
\hline
\end{tabular}

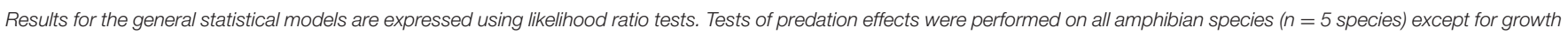

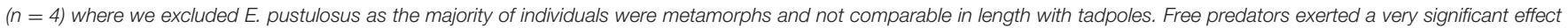

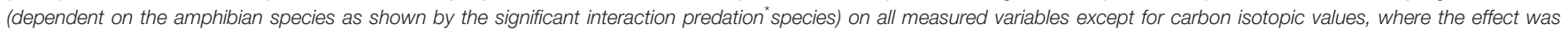

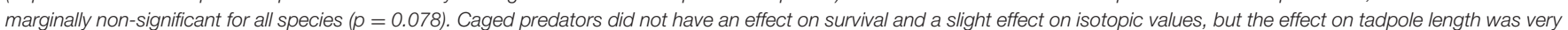

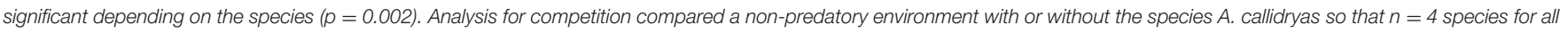

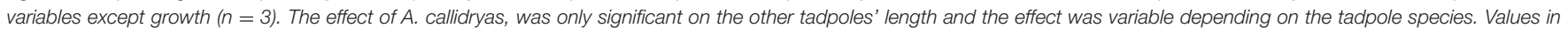
bold indicate $P<0.05$ and asterisks indicate $P<0.1$.

TABLE 2 | Magnitude and effect size of competition and predation on survival, size, and stable isotopic values of the amphibian community.

\begin{tabular}{|c|c|c|c|c|c|c|c|c|c|c|c|c|}
\hline \multirow{4}{*}{ Species } & \multicolumn{6}{|c|}{ Survival } & \multicolumn{6}{|c|}{ Total Length (TL) } \\
\hline & \multicolumn{2}{|c|}{ Competition } & \multicolumn{2}{|c|}{ Uncaged dragonflies } & \multicolumn{2}{|c|}{ Uncaged water bugs } & \multicolumn{2}{|c|}{ Competition } & \multicolumn{2}{|c|}{ Uncaged dragonflies } & \multicolumn{2}{|c|}{ Uncaged water bugs } \\
\hline & Magnitude & Effect size & Magnitude & Effect size & Magnitude & e Effect size & Magnitude & e Effect size & Magnitude & e Effect size & Magnitude & e Effect size \\
\hline & (\%) & (Cohen's d) & $(\%)$ & (Cohen's d) & $(\%)$ & (Cohen's $d$ ) & $(\%)$ & (Cohen's d) & (\%) & (Cohen's d) & $(\%)$ & (Cohen's $d$ ) \\
\hline D. ebraccatus & -1.88 & 0.065 & $-38.46^{\star \star \star}$ & 1.273 & $-23.07^{\star}$ & 0.737 & $-11.92^{\star \star \star}$ & 0.67 & $+18.83^{\star \star}$ & 0.907 & -3.57 & 0.181 \\
\hline D. microcephalus & +5.05 & 0.165 & $-29.04^{\star \star *}$ & 0.972 & -11.73 & 0.435 & $+3^{\star *}$ & 0.304 & +3.72 & 0.28 & -3.11 & 0.384 \\
\hline S. ruber & +6.45 & 0.186 & $-83.33^{\star \star \star}$ & 2.691 & $-40.9^{\star \star \star}$ & 0.687 & $+3.3^{\star \star}$ & 0.176 & $+20.72^{\star \star \star}$ & 1.446 & -1.03 & 0.068 \\
\hline E. pustulosus & +10 & 0.776 & $-88.63^{\text {*** }}$ & 2.964 & $-63.63^{\star \star \star}$ & 1.93 & - & - & - & - & - & - \\
\hline A. callidryas & - & - & $-89.06^{\star \star \star}$ & 3.21 & -4.69 & 0.173 & - & - & +0.75 & 0.064 & -10.57 & 0.889 \\
\hline \multirow[t]{2}{*}{ All species } & +8.1 & 0.777 & $-66.17^{\star \star \star}$ & 1.864 & $-27.05^{\star \star \star}$ & 0.751 & $5.63^{\star \star *}$ & 0.244 & +2.27 & 0.099 & -4.5 & 0.209 \\
\hline & \multicolumn{6}{|c|}{$\delta^{13} \mathrm{C}$} & \multicolumn{6}{|c|}{$\delta^{15} \mathrm{~N}$} \\
\hline D. ebraccatus & +1.27 & 0.332 & $-2.04^{*}$ & 0.702 & $-1.87^{\star}$ & 0.837 & $-9.6^{\star \star \star}$ & 1.25 & +2.58 & 0.926 & $+18.77^{\star \star \star}$ & 1.926 \\
\hline D. microcephalus & -0.75 & 0.192 & -1.6 & 1.042 & +1.28 & 0.776 & -0.51 & 0.081 & -3.88 & 0.495 & +5.37 & 0.786 \\
\hline S. ruber & -3.63 & 0.539 & -3.4 & 1.273 & +1.26 & 0.371 & +0.51 & 0.035 & -18.62 & 3.4 & -8.82 & 0.726 \\
\hline E. pustulosus & -2 & 0.314 & -1.94 & 0.315 & +0.75 & 0.126 & -4.82 & 0.355 & -1.39 & 0.129 & -1.59 & 0.147 \\
\hline A. callidryas & - & - & +0.76 & 0.189 & +0.52 & 0.139 & - & - & $-16.37^{\star \star \star}$ & 1.9 & -2.72 & 0.308 \\
\hline All species & -0.81 & 0.14 & -2.33 & 0.585 & +0.26 & 0.065 & -6.6 & 0.438 & -1.54 & 0.098 & +4.08 & 0.234 \\
\hline
\end{tabular}

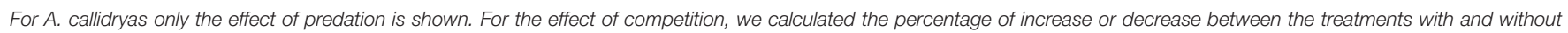

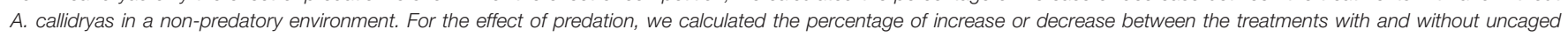

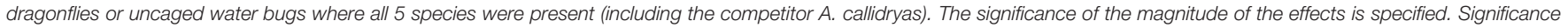

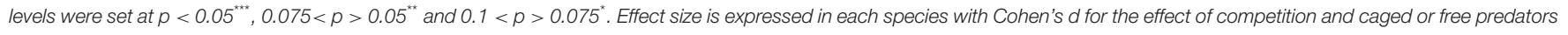
on survival, size and stable isotopes.

D. ebraccatus (by 2.6\%; Figure 5 and Table 2). Uncaged water bugs greatly increased $\delta^{15} \mathrm{~N}$ in $D$. ebraccatus (by $18.8 \%$ ), but decreased $\delta^{15} \mathrm{~N}$ for A. callidryas and S. ruber (by 2.7 and $8.8 \%$, respectively; Figure $\mathbf{5}$ and Table 2). Neither $\delta^{13} \mathrm{C}$ nor $\delta^{15} \mathrm{~N}$ values varied with predation in $E$. pustulosus.
Caged predators also affected the stable isotope values of different tadpole species (Figure 5 and Appendix 2 Tables B1B5 in Supplementary Material), as indicated by the marginally significant "caged predator $\times$ species" interaction for both $\delta^{13} \mathrm{C}$ and $\delta^{15} \mathrm{~N}(P=0.06$, Table 1$)$. Looking at tadpole species individually, caged dragonflies increased the value of $\delta^{13} \mathrm{C}$ of $A$. 

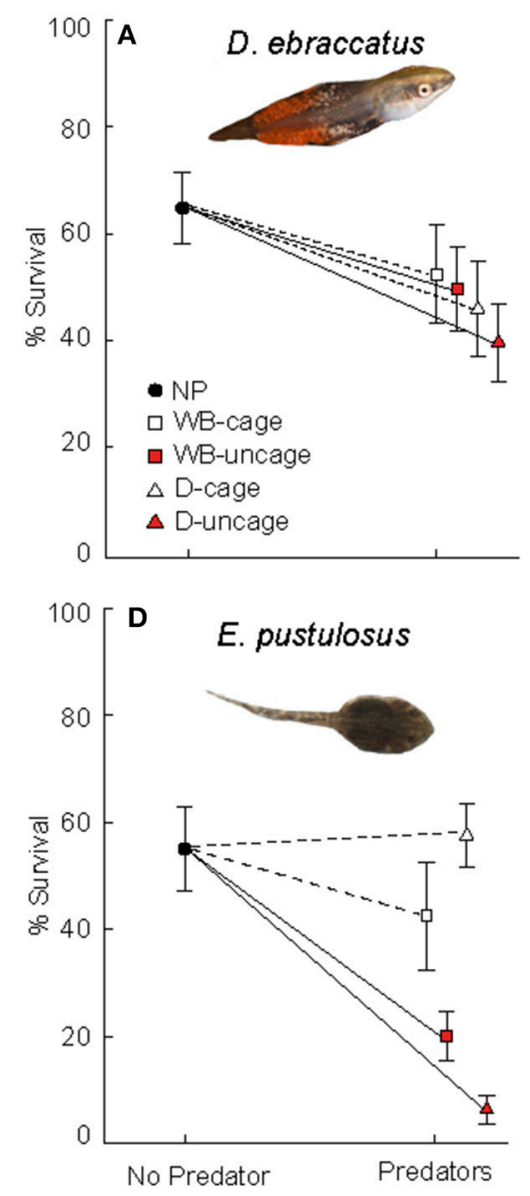

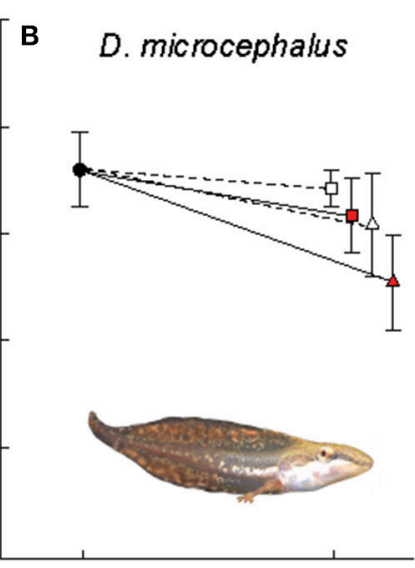

E

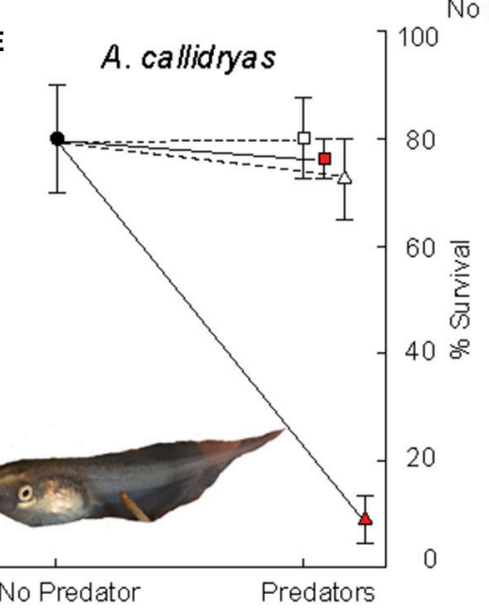

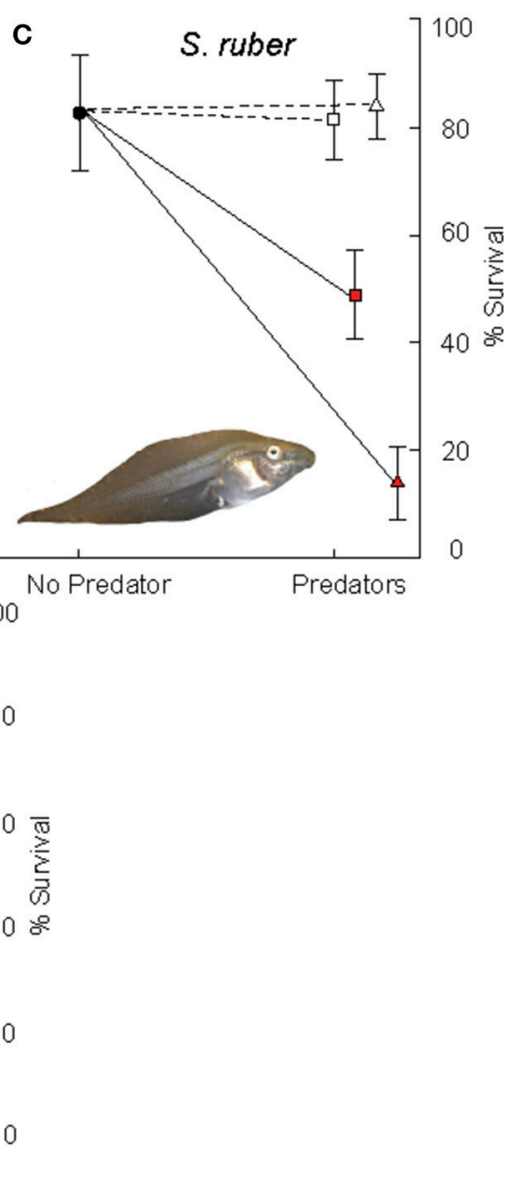

FIGURE 2 | Survival (mean \pm SE, \%) of: (A) D. ebraccatus; (B) D. microcephalus; (C) S. ruber; (D) E. pustulosus; and (E) A. callidryas in a non-predatory environment (left, No Predator) and in each of the 4 predatory treatments (right) of this experiment. Treatments with water bugs (WB) are represented with squares and dragonflies (D) are represented with triangles. Open white symbols and dashed lines represent caged predators and red filled symbols represent free predators. All tadpole photos by JT.

callidryas by $3.56 \%(P=0.04)$ and increased the value of $\delta^{15} \mathrm{~N}$ of $A$. callidryas (by $12 \%, P=0.03$ ), D. ebraccatus (by $15.9 \%$, $P=0.004$ ) and D. microcephalus (by $8.3 \%, P=0.005$ ). Caged water bugs only had a significant effect of increasing $\delta^{15} \mathrm{~N}$ in $D$. ebraccatus (by $11.9 \%, P=0.017$ ).

We also quantified the $\delta^{13} \mathrm{C}$ and $\delta^{15} \mathrm{~N}$ of various potential food sources in the mesocosms. As expected, zooplankton had the highest $\delta^{15} \mathrm{~N}$ values followed by periphyton, whereas sediment and plants had the lowest. Periphyton had the highest $\delta^{13} \mathrm{C}$ values, whereas phytoplankton had the lowest (Figure 5).

\section{DISCUSSION}

Competition and predation are two key factors influencing the structure and dynamics of ecological communities (Paine, 1966; Vellend, 2010; Arribas et al., 2014). These two factors often occur at the same time and the mere presence of predators or competitors, in addition to their density-dependent effects on prey, may force organisms with phenotypic plasticity to shift aspects of their phenotype (e.g., behavior, feeding structures, metabolism) thereby altering the realized trophic niche of the species (Levin, 2009; Caut et al., 2013). The relative importance of competition and predation is largely dependent upon factors such as biogeography, the type of predators and competitors, whether the habitat is permanent or ephemeral, or the degree of niche segregation (Azevedo-Ramos et al., 1999; Gurevitch et al., 2000; Chase et al., 2002). In our experiment, we quantified the effects of predation and competition on the trophic ecology of a Neotropical larval amphibian guild and found that predators generally had much stronger effects on growth, survival and feeding ecology than competitors.

Predators can differentially affect prey survival and alter their growth trajectories by non-randomly consuming individuals of different size classes (Claessen et al., 2002), by inducing novel behavioral or morphological phenotypes (Lima, 1998), and through thinning and releasing resources for the remaining individuals (Van Buskirk and Yurewicz, 1998; Brodin and Johansson, 2002). Moreover, these effects of predators often have cascading consequences for community structure (Post et al., 2008; Arribas et al., 2014). 


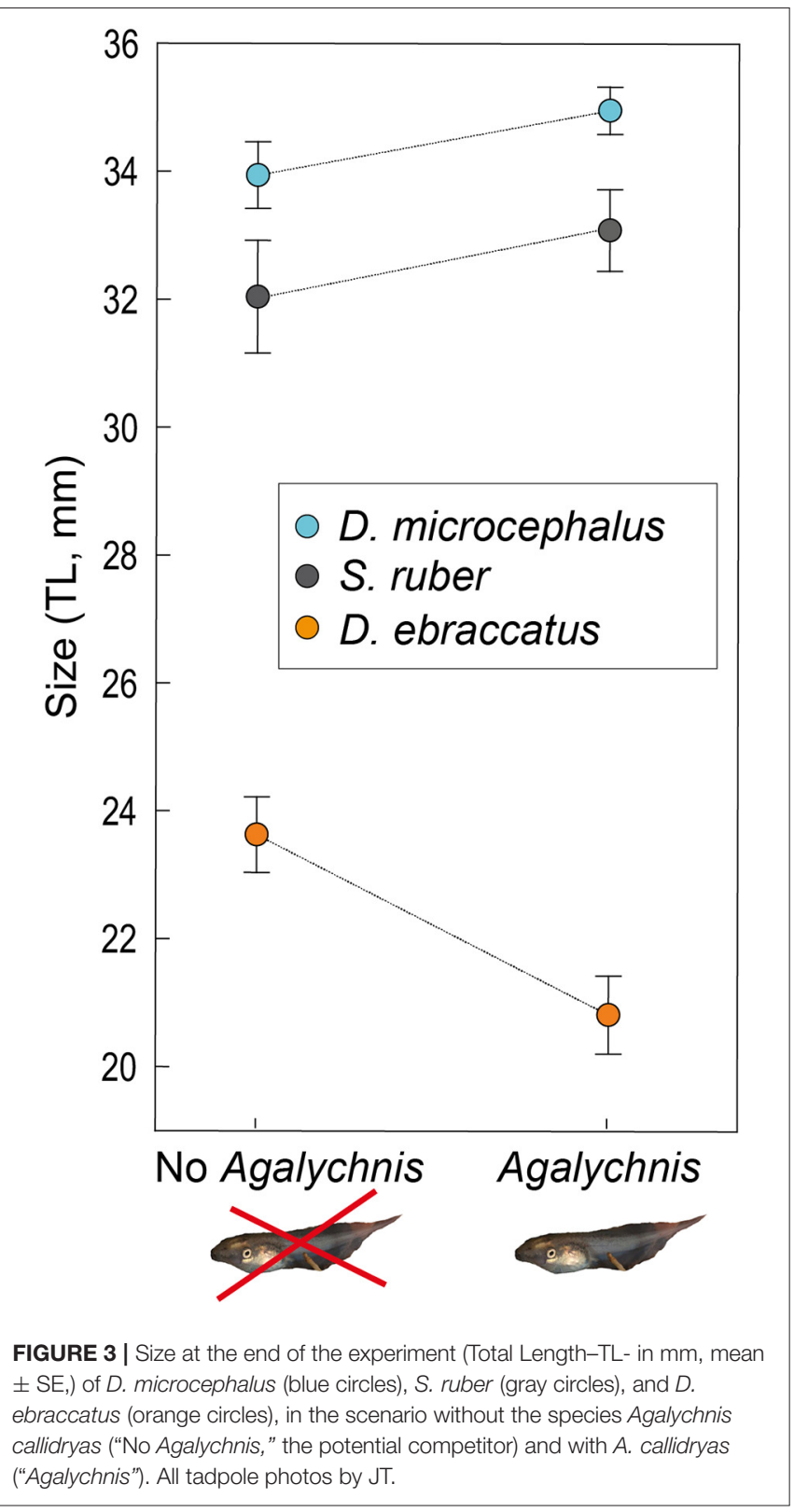

We observed interspecific competition in our system, although it was rather asymmetrical across species. Agalychnis callidryas tadpoles were the largest in our experiment, and we expected all other species to experience detrimental effects from competition with them. However, only D. ebraccatus was negatively impacted by competition from $A$. callidryas, reducing its growth rate as found in one other study (Gonzalez et al., 2011). Counterintuitively, the size of $D$. microcephalus and $S$. ruber both appeared to increase in the presence of $A$. callidryas (Figure 3). This indicates that $A$. callidryas competes most intensely with just one species in the guild, and other species may therefore experience a cascading benefit from its presence, perhaps through a suppression of competitive effects of $D$. ebraccatus.

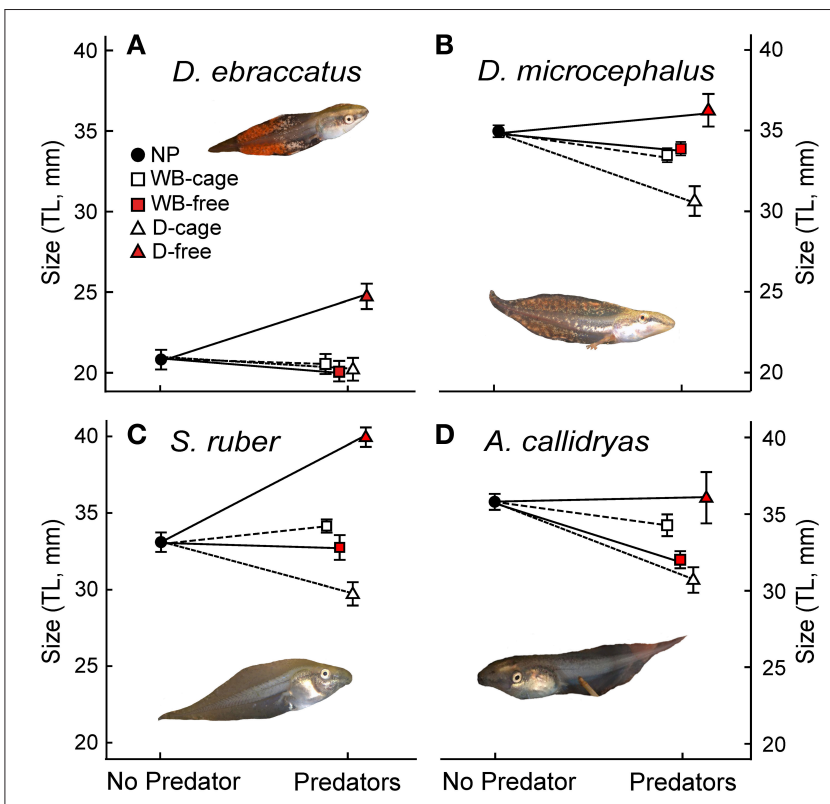

FIGURE 4 | Size at the end of the experiment (Total Length-TL- in mm, mean \pm SE,) of: (A) D. ebraccatus; (B) D. microcephalus; (C) S. ruber; and (D) A. callidryas in a non-predatory environment (left, No Predator) and in each of the 4 predatory treatments (right) of this experiment. Treatments with water bugs (WB) are represented with squares and dragonflies (D) are represented with triangles. Open white symbols and dashed lines represent caged predators and red filled symbols represent free predators. All tadpole photos by JT.

Nevertheless, we found that predation played a more important role than competition in shaping the structure of our tropical tadpole guild, including effects on prey growth, survival and feeding niche. Freely roaming predators greatly reduced survival of all amphibian species. Dragonfly nymphs had a very strong impact, reducing survival of three species (E. pustulosus, A. callidryas and S. ruber) by more than $80 \%$ and subsequently increasing growth of the surviving larvae of all species by 9$26 \%$ (Table 2). Larger body size of surviving tadpoles could result from a combination of reduced competition via thinning and/or size selective predation if predators preyed more easily on smaller tadpoles. Water bugs were less effective predators than dragonflies, preferentially consuming E. pustulosus and S. ruber, and generally reducing growth in all species. Most individuals of E. pustulosus had already metamorphosed by the end of the experiment, and predation by water bugs may have occurred during metamorphosis, when amphibians are highly vulnerable (Touchon et al., 2013, 2015). This seems particularly likely since water bugs generally forage at the top of the water column while E. pustulosus tadpoles are expected to stay toward the bottom. It is not uncommon for two predators in the same environment to have substantially different effects on prey species (Atwood et al., 2014). Given the strong predation effects previously documented on A. callidryas and D. ebraccatus (Vonesh and Warkentin, 2006; Gonzalez et al., 2011; Touchon et al., 2013), it appears the presence of multiple tadpole prey species in the environment reduces overall predation risk. For example, dragonflies rapidly decimated D. ebraccatus in one study (Gonzalez et al., 2011), 
TABLE 3 | Effects of competition on $\delta^{15} \mathrm{~N}$, with respect to predation.

\begin{tabular}{lllll}
\hline Treatment & \multicolumn{2}{c}{ D. ebraccatus } & D. microcephalus S. ruber & E. pustulosus \\
\hline No predator & Decrease $^{\star *}$ & No effect & No effect & No effect \\
Caged water bug No effect & No effect & No effect & No effect \\
Free water bug & No effect & No effect & Decrease* & No effect \\
Caged dragonfly & Increase* & No effect & No effect & No effect \\
Free dragonfly & Decrease $^{\star *}$ & Decrease & Decrease & No effect
\end{tabular}

We specify when the diet of a species is not affected by A. callidryas (No effect) and when the presence of either free or caged predators affects the isotopic values of $\delta^{15} \mathrm{~N}$. Significance levels were set at $p<0.05^{\star \star \star}, 0.075<p>0.05^{\star \star}$ and $0.1<p>0.075^{\star}$.

consuming more than $90 \%$ of tadpoles in only 8 days, whereas during our 4 -week experiment only $38 \%$ of $D$. ebraccatus tadpoles were consumed. In view of these results, it is clear that realistic estimates of predation rates need to take into account other biotic elements of the natural community.

Direct consumption is not the only way that predators can affect community structure (Hammill et al., 2015). Predators can have many non-lethal, indirect effects on morphology, behavior, or life history which also have important consequences for community dynamics (Lima, 1998; Agrawal, 2001). The nonlethal presence of caged dragonflies reduced tadpole growth in most species, as the perceived risk of predation through chemical cues typically causes reduced activity and lower metabolism (Van Buskirk and Yurewicz, 1998; Werner and Peacor, 2003). We did not detect indirect effects of water bugs, although phenotypic responses to these predators have been seen in other studies (McIntyre et al., 2004; Vonesh and Warkentin, 2006; Touchon and Warkentin, 2011).

\section{Shifts in Trophic Status}

We used stable isotope analyses to assess the realized feeding niche of each member of our tadpole community. Stable isotopes constitute a valuable tool to evaluate the trophic status of individuals, and represent the combination of food sources an organism has accumulated over time (Kilham et al., 2009). The trophic discrimination of nitrogen and carbon stable isotopes is the change in isotopic ratios between consumer and resource $(\Delta)$. Isotopic values of consumers are usually enriched with respect to their sources by $3-4 \%$ for $\delta^{15} \mathrm{~N}$ but this value is very low for $\delta^{13} \mathrm{C}$ (Peterson and Fry, 1987). Therefore, higher values of $\delta^{15} \mathrm{~N}$ are indicative of a higher trophic position (i.e., consuming organisms higher in the food web; Fry, 2006; Newsome et al., 2007) whereas changes in $\delta^{13} \mathrm{C}$ typically indicates different carbon sources (Post, 2002). However, the trophic discrimination of nitrogen and carbon stable isotopes in tropical aquatic systems differ from their temperate counterparts, with lower $\Delta^{15} \mathrm{~N}(1-2 \%$ ) and higher $\Delta^{13} \mathrm{C}(1-1.6 \%$ ) values (Kilham et al., 2009).

Stable isotopes helped us identify that tadpoles altered their trophic status in response to the presence of predators and competitors, although different species responded in different ways. For example, both types of free roaming predators caused $D$. ebraccatus to shift to a higher trophic level and A. callidryas and $S$. ruber to a lower trophic level. In a freshwater food web similar to ours, a shift to a higher trophic level was seemingly due to an increased proportion of zooplankton in the diet (Costa and Vonesh, 2013a). However, in species such as D. ebraccatus, an increase in trophic niche with predators may result from increased foraging in the water column and a reduced dependence on grazing periphyton. Predator effects on $A$. callidryas or $S$. ruber trophic status likely stem from a similar effect; if predators cause tadpoles to change where they are foraging, tadpoles may see a concomitant shift in trophic ecology. Similarly, competition with A. callidryas caused D. ebraccatus and E. pustulosus to feed at a lower trophic level, whereas competition had essentially no effect on D. microcephalus and S. ruber. Thus, the same predator or competitor can have very different, even opposing, effects on different species. These effects may stem from adaptive shifts of the different tadpole species, but are more likely the direct result of changes in foraging behavior resulting from the presence of predators or competitors. However, more studies will be needed to assess this hypothesis.

Not only did competition and predation have species-specific effects, but the interaction between competition and predation differed across prey taxa as well. These effects were primarily seen for nitrogen, but one species (S. ruber) also showed significant changes in carbon. An example of the interplay between predation and competition can be seen when looking at the effects of A. callidryas on the smaller D. ebraccatus (Appendix 1 Table A1 in Supplementary Material). In the absence of predators, A. callidryas drove down the trophic level of D. ebraccatus. However, free water bugs removed the effect of competition and caged dragonfly nymphs reversed it. Similarly, A. callidryas had no effect on $S$. ruber feeding in the absence of predators, but when coupled with either free water bugs or dragonflies, competition caused a large decrease in trophic level. Our results demonstrate that competition and predation interact to affect feeding ecology in complex ways. Certainly thinning of dominant species drives some of these patterns, but thinning alone does not appear to fully explain our results. Clearly there are inherent interspecific differences in trophic level and feeding. For example, the two most closely related species (the two Dendropsophus species) fed at very different trophic levels, with $D$. ebraccatus generally feeding at the highest carbon and nitrogen levels of all five species (Figure 5; Appendix 1 Table A1 in Supplementary Material). Focused assays of feeding behavior and experimental diets to estimate discriminant factors will be needed in order to be able to relate the shift in isotopic values with changes in diet composition (Caut et al., 2013; Arribas et al., 2014). Overall, we observed a stronger change in $\delta^{15} \mathrm{~N}$ than in $\delta^{13} \mathrm{C}$ values across experimental treatments, indicating that induced shifts in trophic level were more pronounced than actual changes in the food sources. Such a pattern likely results from changes in the relative composition of otherwise diverse diets, rather than marked shifts from one food type to another (Arribas et al., 2014).

In summary, we demonstrate that predation and, to a lesser extent, competition, have strong top-down effects structuring a guild of Neotropical amphibian larvae and their trophic status. Predation and competition differentially altered growth, survival and the trophic niches of multiple amphibian species, with potential downstream ramifications for resource assimilation and 

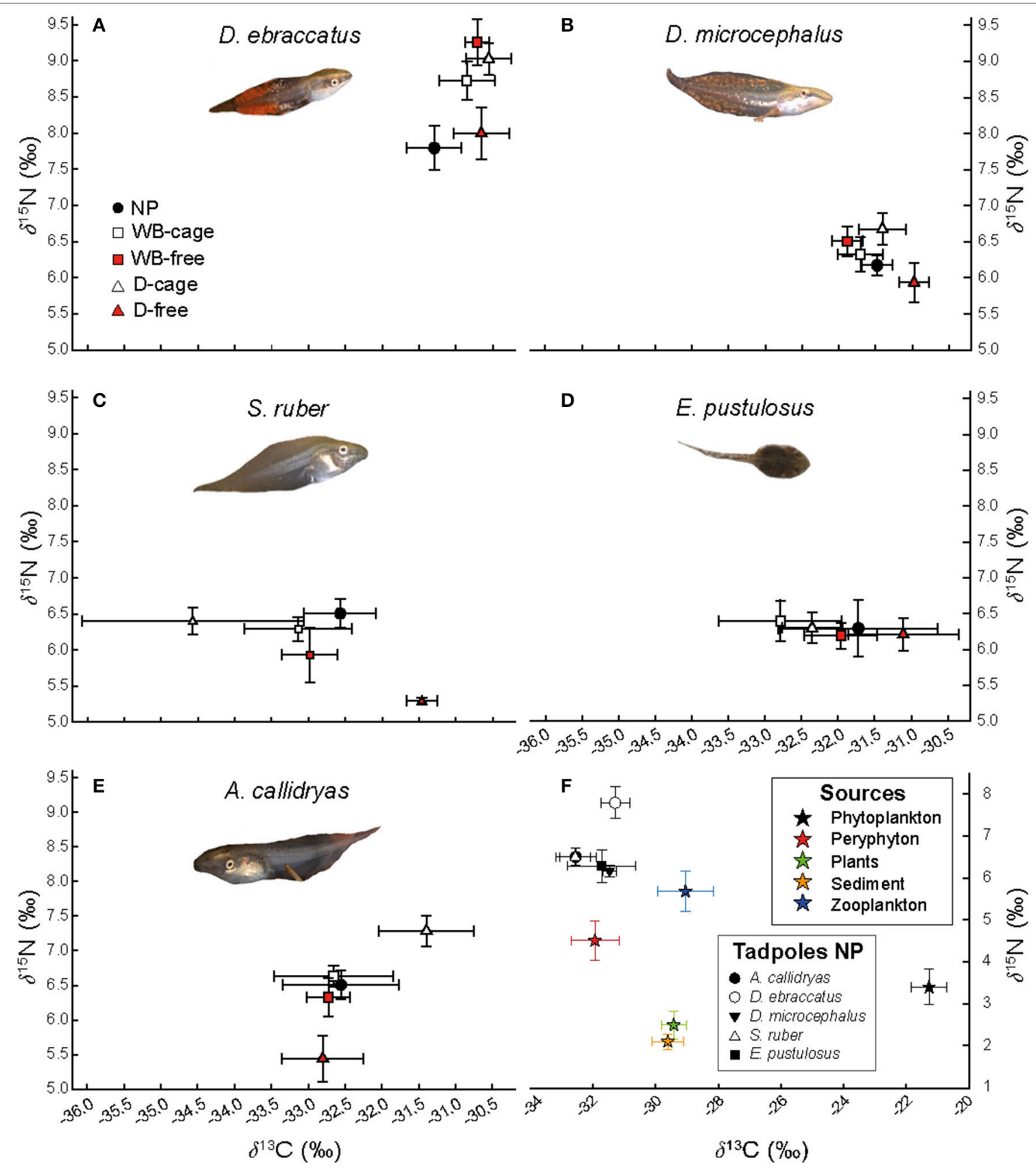

FIGURE 5 | Biplot of stable isotopic values $\left(\delta^{13} \mathrm{C}\right.$ and $\delta^{15} \mathrm{~N}$, mean $\left.\pm \mathrm{SE}\right)$ for each tadpole species included in the mesocosms: (A) $D$. ebraccatus; (B) $D$. microcephalus; (C) S. ruber; (D) E. pustulosus; (E) A. callidryas. (F) Represents the isotopic values of potential food sources in the mesocosms (mean $\pm \mathrm{SE}$ ) and the isotopic values of the five amphibian species in a predator-free environment (NP). $\delta^{13} \mathrm{C}$ and $\delta^{15} \mathrm{~N}$ values are represented in the absence of predators (NP, black circles) and in each of the four treatments with predators [treatments with water bugs (WB) are represented with squares and dragonflies (D) are represented with triangles, whereas white or red color indicate caged and uncaged predators respectively].

energy flow between aquatic and terrestrial habitats. Longerterm studies of trophic alterations and structure in aquatic communities are needed to clarify the ecological consequences and cascading effects of amphibian losses in food webs across the world, given that they are the most endangered group of vertebrates (Stuart et al., 2004; Wake and Vredenburg, 2008).

\section{ETHICS STATEMENT}

We conducted this research under permission from Autoridad Nacional del Ambiente de Panamá (Permit N. SE/A-46-12) and the Smithsonian Tropical Research Institute. 


\section{AUTHOR CONTRIBUTIONS}

JT and IG-M conceived the study and designed the experiment. RA and JT setup the mesocosms and collected the animals. RA conducted the experiment and collected the data. RA analyzed the data with statistical input from JT and IG-M. RA, JT, and IG-M wrote the manuscript.

\section{ACKNOWLEDGMENTS}

We thank the Autoridad Nacional del Ambiente de Panamá for permission to conduct this research in Panama (Permiso No. SE/A-46-12) and the Smithsonian Tropical Research Institute for use of their facilities and logistical support. We also thank the unconditional help in the field and experimental work from

\section{REFERENCES}

Ackerly, D. D. (2003). Community assembly, niche conservatism, and adaptive evolution in changing environments. Int. J. Plant Sci. 164, S165-S184. doi: $10.1086 / 368401$

Agrawal, A. A. (2001). Phenotypic plasticity in the interactions and evolution of species. Science 294, 321-326. doi: 10.1126/science.1060701

Alford, R. A. (1999). "Ecology: resource use, competition, and predation," in Tadpoles: The Biology of Anuran Larvae, eds R. McDiarmid and R. Altig (Chicago: University of Chicago Press), 240-278.

Altig, R., Whiles, M. R., and Taylor, C. L. (2007). What do tadpoles really eat? Assessing the trophic status of an understudied and imperiled group of consumers in freshwater habitats. Freshw. Biol. 52, 386-395. doi: 10.1111/j.1365-2427.2006.01694.x

Alzmann, N., Kohler, B., and Maier, G. (1999). Spatial distribution, food and activity of Gomphus pulchellus SELYS 1840 (Insecta; Odonata; Gomphidae) from a still water habitat. Int. Rev. Hydrobiol. 84, 299-313.

Arribas, R., Diaz-Paniagua, C., and Gomez-Mestre, I. (2014). Ecological consequences of amphibian larvae and their native and alien predators on the community structure of temporary ponds. Freshw. Biol. 59, 1996-2008. doi: $10.1111 /$ fwb. 12402

Arribas, R., Díaz-Paniagua, C., Caut, S., and Gomez-Mestre, I. (2015). Stable isotopes reveal trophic partitioning and trophic plasticity of a larval amphibian guild. PLoS ONE 10:e0130897. doi: 10.1371/journal.pone.0130897

Atwood, T. B., Hammill, E., Srivastava, D. S., and Richardson, J. S. (2014). Competitive displacement alters top-down effects on carbon dioxide concentrations in a freshwater ecosystem. Oecologia 175, 353-361. doi: 10.1007/s00442-013-2877-3

Azevedo-Ramos, C., Magnusson, W. E., and Bayliss, P. (1999). Predation as the key factor structuring tadpole assemblages in a savanna area in Central Amazonia. Copeia 1, 22-33.

Benjamini, Y., and Hochberg, Y. (1995). Controlling the false discovery rate: a practical and powerful approach to multiple testing. J. R. Stat. Soc. Ser. B 57, 289-300.

Berg, M. P., and Bengtsson, J. (2007). Temporal and spatial variability in soil food web structure. Oikos 116, 1789-1804. doi: 10.1111/j.2007.0030-1299.15748.x

Bolnick, D. I., and Preisser, E. L. (2005). Resource competition modifies the strength of trait-mediated predator-prey interactions. Ecology 86, 2771-2779. doi: 10.1890/04-1249

Bowes, R. E., Lafferty, M. H., and Thorp, J. H. (2014). Less means more: nutrient stress leads to higher $\delta 15 \mathrm{~N}$ ratios in fish. Freshw. Biol. 59, 1926-1931. doi: $10.1111 /$ fwb. 12396

Brodin, T., and Johansson, F. (2002). Effects of predator-induced thinning and activity changes on life history in a damselfly. Oecologia 132, 316-322. doi: $10.1007 /$ s00442-002-0938-0
H. J. Lee, G. Toral, K. Warkentin, T. Hammer, P. Marting, U. Somjee, I. Hoffmann, and any others who passed by and gave a hand. The mesocosm array was made possible by an NSF grant to K. Warkentin and J. Vonesh. Funding for this study was provided by grant CGL2009-11123 and grant CGL2012-4044 from Ministerio de Economía y Competitividad to IG-M, dissertation grant BES2010-042243 and a short stay grant EEBB-I-12-05583 to RA and NSF grant IRFP-1064566 to JT.

\section{SUPPLEMENTARY MATERIAL}

The Supplementary Material for this article can be found online at: https://www.frontiersin.org/articles/10.3389/fevo. 2018.00028/full\#supplementary-material

Caut, S., Angulo, E., Díaz-Paniagua, C., and Gomez-Mestre, I. (2013). Plastic changes in tadpole trophic ecology revealed by stable isotope analysis. Oecologia 173, 95-105. doi: 10.1007/s00442-012-2428-3

Chase, J. M., Abrams, P. A., Grover, J. P., Diehl, S., Chesson, P., Holt, R. D., et al. (2002). The interaction between predation and competition: a review and synthesis. Ecol. Lett. 5, 302-315. doi: 10.1046/j.1461-0248.2002.00315.x

Claessen, D., Van Oss, C., de Roos, A. M., and Persson, L. (2002). The impact of size-dependent predation on population dynamics and individual life history. Ecology 83, 1660-1675. doi: 10.1890/0012-9658(2002)083[1660:TIOSDP]2.0. $\mathrm{CO} ; 2$

Corbet, P. S. (1962). A Biology of Dragonflies. London: Witherby.

Costa, Z. J., and Vonesh, J. R. (2013a). Interspecific differences in the direct and indirect effects of two neotropical hylid tadpoles on primary producers and zooplankton. Biotropica 45, 503-510. doi: 10.1111/btp.12032

Costa, Z. J., and Vonesh, J. R. (2013b). Prey subsidy or predator cue? Direct and indirect effects of caged predators on aquatic consumers and resources. Oecologia 173, 1481-1490. doi: 10.1007/s00442-013-2702-Z

DeNiro, M., and Epstein, S. (1981). Influence of diet on the distribution of nitrogen isotopes in animals. Geochim. Cosmochim. Acta 45, 341-351. doi: 10.1016/0016-7037(81)90244-1

Fry, B. (2006). Stable Isotope Ecology. Springer: New York, NY.

Gómez-Campos, E., Borrell, A., Cardona, L., Forcada, J., and Aguilar, A. (2011). Overfishing of small pelagic fishes increases trophic overlap between immature and mature striped dolphins in the Mediterranean Sea. PLoS ONE 6:e24554. doi: 10.1371/journal.pone.0024554

Gomez-Mestre, I., and Tejedo, M. (2002). Geographic variation in asymmetric competition: a case study with two larval anuran species. Ecology 83, 2102-2111. doi: 10.1890/0012-9658(2002)083[2102:GVIACA]2.0.CO;2

Gomez-Mestre, I., Wiens, J. J., and Warkentin, K. M. (2008). Evolution of adaptive plasticity: risk-sensitive hatching in neotropical leaf-breeding treefrogs. Ecol. Monogr. 78, 205-224. doi: 10.1890/07-0529.1

Gonzalez, S. C., Touchon, J. C., and Vonesh, J. R. (2011). Interactions between competition and predation shape early growth and survival of two neotropical hylid tadpoles. Biotropica 43, 633-639. doi: 10.1111/j.1744-7429.2010.00748.x

Gurevitch, J., Morrison, J. A., and Hedges, L. V. (2000). The interaction between competition and predation: a meta-analysis of field experiments. Am. Nat. 155, 435-453. doi: 10.1086/303337

Hammill, E., Atwood, T. B., and Srivastava, D. S. (2015). Predation threat alters composition and functioning of bromeliad ecosystems. Ecosystems 18, 857-866. doi: 10.1007/s10021-015-9866-9

Hero, A. J., Magnusson, W. E., Rocha, C. F. D., Catterall, C. P., Biotropica, S., Mar, N., et al. (2001). Antipredator defenses influence the distribution of amphibian prey species in the central amazon rain forest. Biotropica 33, 131-141. doi: 10.1111/j.1744-7429.2001.tb 00163.x 
Kilham, S. S., Hunte-Brown, S. S. M., Verburg, P., Pringle, C. M., Whiles, M. R., Lips, K. R., et al. (2009). Challenges for interpreting stable isotope fractionation of carbon and nitrogen in tropical aquatic ecosystems. Verhandlungen Int. Vereinigung Limnol. 30, 749-753. doi: 10.1080/03680770.2009.11902231

Kozak, K. H., and Wiens, J. J. (2012). Phylogeny, ecology, and the origins of climate-richness relationships. Ecology 93, 167-181. doi: 10.1890/110542.1

Layman, C. A., Araujo, M. S., Boucek, R., Hammerschlag-Peyer, C. M., Harrison, E., Jud, Z. R., et al. (2012). Applying stable isotopes to examine food-web structure: an overview of analytical tools. Biol. Rev. Camb. Philos. Soc. 87, 545-562. doi: 10.1111/j.1469-185X.2011.00208.x

Legendre, P., Borcard, D., and Peres-Neto, P. R. (2005). Analyzing beta diversity: partitioning the spatial variation of community composition data. Ecol. Monogr. 75, 435-450. doi: 10.1890/05-0549

Levin, D. A. (2009). Flowering-time plasticity facilitates niche shifts in adjacent populations. New Phytol. 183, 661-666. doi: 10.1111/j.1469-8137.2009. 02889.x

Lima, S. L. (1998). Nonlethal effects in the ecology of predator-prey interactions What are the ecological effects of anti-predator decision-making? Bioscience 48, 25-34. doi: 10.2307/1313225

Mahato, M., and Johnson, D. A. N. M. (1991). Invasion of the bays Mountain Lake dragonfly assemblage by Dromogomphus spinosus (Odonata: Gomphidae). J. North Am. Benthol. Soc. 10, 165-176.

McIntyre, P. B., Baldwin, S., and Flecker, A. S. (2004). Effects of behavioral and morphological plasticity on risk of predation in a Neotropical tadpole. Oecologia 141, 130-138. doi: 10.1007/s00442-004-1652-x

Morin, P. J. (1983). Predation, competition, and the composition of larval anuran guilds. Ecol. Monogr. 53, 119-138. doi: 10.2307/1942491

Morlon, H., Kefi, S., and Martinez, N. D. (2014). Effects of trophic similarity on community composition. Ecol. Lett. 17, 1495-1506. doi: 10.1111/ele. 12356

Mowles, S. L., Rundle, S. D., and Cotton, P. A. (2011). Susceptibility to predation affects trait-mediated indirect interactions by reversing interspecific competition. PLoS ONE 6:e23068. doi: 10.1371/journal.pone.0023068

Newsome, S. D., Martinez del Rio, C., Bearhop, S., and Phillips, D. L. (2007). A niche for isotopic ecology. Front. Ecol. Environ. 5, 429-436. doi: $10.1890 / 060150.01$

Nystrom, P., Svensson, O., Lardner, B., Bronmark, C., and Graneli, W. (2001). The influence of multiple introduced predators on a littoral pond community. Ecology 82, 1023-1039. doi: 10.1890/0012-9658(2001)082[1023:TIOMIP]2.0. $\mathrm{CO} ; 2$

Paine, R. T. (1966). Food web complexity and species diversity. Am. Nat. 100, 65-75.

Pascual, M., and Dunne, J. A. (2005). Ecological Networks: Linking Structure to Dynamics in Food Webs. Oxford: Oxford University Press.

Peacor, S. D. (2006). Behavioural response of bullfrog tadpoles to chemical cues of predation risk are affected by cue age and water source. Hydrobiologia 573, 39-44. doi: 10.1007/s10750-006-0256-3

Peterson, B. J. B. J., and Fry, B. (1987). Stable isotopes in ecosystem studies. Annu. Rev. Ecol. Syst. 18, 293-320. doi: 10.1146/annurev.es.18.110187.001453

Pimm, S. L. (1982). Food Webs. Dordrecht: Springer.

Post, D. M. (2002). Using stable isotopes to estimate trophic position: models, methods, and assumptions. Ecology 83, 703-718. doi: 10.2307/3071875

Post, D. M., Palkovacs, E. P., Schielke, E. G., Dodson, S. I., (2008). Intraspecific variation in a predator affects community structure and cascading trophic interactions. Ecology 89, 2019-2032. doi: 10.1890/07-1216.1

Prasad, R. P., and Snyder, W. E. (2006). Diverse trait-mediated interactions in a multi-predator, multi-prey community. Ecology, 87, 1131-1137. doi: 10.1890/ 0012-9658(2006)87[1131:DTIIAM]2.0.CO;2

Rand, A. S. (1983). "Physalaemus pustulosus," in Costa Rican Natural History, ed D. Janzen (Chicago: University of Chicago Press), 412-415.

Rasband, W. S. (2012). ImageJ, US. Available online at: http://imagej.nih.gov/ij/

$\mathrm{R}$ Core Team (2013). R: A Language and Environment for Statistical Computing.Vienna: R Foundation for Statistical Computing. Available online at: http://www.r-project.org/

Relyea, R. A. (2000). Trait-mediated indirect effects in larval anurans: reversing competition with the threat of predation. Ecology 81, 2278-2289. doi: $10.2307 / 177114$
Ryan, M. J. (1985). The Tungara Frog: A Study in Sexual Selection and Communication. University of Chicago Press. Available online at: http://books. google.com/books?hl=es\&lr=\&id=ZRXmq1-qVlsC\&pgis $=1$

Schmitz, O. J., Krivan, V., and Ovadia, O. (2004). Trophic cascades: the primacy of trait-mediated indirect interactions. Ecol. Lett. 7, 153-163. doi: 10.1111/j.1461-0248.2003.00560.x

Schriever, T. A., and Williams, D. D. (2013). Ontogenetic and individual diet variation in amphibian larvae across an environmental gradient. Freshw. Biol. 58, 223-236. doi: 10.1111/fwb. 12044

Soininen, J. (2010). Species turnover along abiotic and biotic gradients: patterns in space equal patterns in time? Bioscience 60, 433-439. doi: $10.1525 /$ bio. 2010.60 .6 .7

Stuart, S. N., Chanson, J. S., Cox, N. A., Young, B. E., Rodrigues, A. S., Fischman, D. L., et al. (2004). Status and trends of amphibian declines and extinctions worldwide. Science 306, 1783-1786. doi: 10.1126/science.1103538

Svanbäck, R., and Bolnick, D. I. (2007). Intraspecific competition drives increased resource use diversity within a natural population. Proc. R. Soc. B Biol. Sci. 274, 839-844. doi: 10.1098/rspb.2006.0198

Touchon, J. C., Jiménez, R. R., Abinette, S. H., Vonesh, J. R., and Warkentin, K. M. (2013). Behavioral plasticity mitigates risk across environments and predators during anuran metamorphosis. Oecologia 173, 801-811. doi: 10.1007/s00442-013-2714-8

Touchon, J. C., McCoy, M. W., Landberg, T., Vonesh, J. R., and Warkentin, K. M. (2015). Putting u/g in a new light: plasticity in life history switch points reflects fine-scale adaptive responses. Ecology 96, 2192-2202. doi: 10.1890/14-1301.1

Touchon, J. C., and Vonesh, J. R. (2016). Variation in abundance and efficacy of tadpole predators in a Neotropical pond community. J. Herpetol. 50, 113-119. doi: 10.1670/14-111

Touchon, J. C., and Warkentin, K. M. (2008). Reproductive mode plasticity: aquatic and terrestrial oviposition in a treefrog. Proc. Natl. Acad. Sci. U.S.A. 105, 7495-7499. doi: 10.1073/pnas.0711579105

Touchon, J. C., and Warkentin, K. M. (2011). Thermally contingent plasticity: temperature alters expression of predator-induced colour and morphology in a Neotropical treefrog tadpole. J. Anim. Ecol. 80, 79-88. doi: $10.1111 /$ j.1365-2656.2010.01765.x

Underwood, T. (1986). "The analysis of competition by field experiments," in Community Ecology: Pattern and Process, eds J. Kikkawa and D. J. Anderson (Melbourne, VIC: Blackwell Scientific), 240-268.

Van Buskirk, J., and Yurewicz, K. L. (1998). Effects of predators on prey growth rate: relative contributions of thinning and reduced activity. Oikos 82, 20-28. doi: $10.2307 / 3546913$

Vellend, M. (2010). Conceptual synthesis in community ecology. Q. Rev. Biol. 85, 183-206. doi: 10.1086/652373

Verburg, P., Kilhamt, S. S., Pringle, C. M., Lips, K. R., Drake, D. L., Kilham, S. S., et al. (2007). A stable isotope study of a neotropical stream food web prior to the extirpation of its large amphibian community. J. Trop. Ecol. 23, 643-651. doi: 10.1017/S0266467407004518

Verhoeven, K. J. F., Simonsen, K. L., and McIntyre, L. M. (2005). Implementing false discovery rate control: increasing your power. Oikos 108, 643-647. doi: 10.1111/j.0030-1299.2005.13727.x

Vonesh, J. R., and Warkentin, K. M. (2006). Opposite shifts in size at metamorphosis in response to larval and metamorph predators. Ecology 87, 556-562. doi: 10.1890/05-0930

Wake, D. B., and Vredenburg, V. T. (2008). Are we in the midst of the sixth mass extinction? A view from the world of amphibians. Proc. Natl. Acad. Sci. U.S.A. 105, 11466-11473. doi: 10.1073/pnas.0801921105

Warkentin, K. M. (1999). Effects of hatching age on development and hatchling morphology in the red-eyed treefrog, Agalychnis callidryas. Biol. J. Linn. Soc. 68, 443-470.

Wassersug, R. J. (1980). Internal oral features of larvae from eight anuran families: functional, systematic, evolutionary and ecological considerations. Misc. Publ. Museum Nat. Hist. Univ. Kansas 68, 1-146.

Wells, K. D. (2007). The Ecology and Behavior of Amphibians. University of Chicago Press. Available online at: http://books.google.com/books?hl=es\&lr=\& $\mathrm{id}=\mathrm{eDKEKy} 5$ JJbIC\&pgis $=1$

Werner, E. E., and Peacor, S. D. (2003). A review of trait-mediated indirect interactions in ecological communities. Ecology 84, 1083-1100. doi: 10.1890/ 0012-9658(2003)084[1083:AROTII]2.0.CO;2 
Whiles, M. R., Gladyshev, M. I., Sushchik, N. N., Makhutova, O. N., Kalachova, G. S., Peterson, S. D., et al. (2010). Fatty acid analyses reveal high degrees of omnivory and dietary plasticity in pond-dwelling tadpoles. Freshw. Biol. 55, 1533-1547. doi: 10.1111/j.1365-2427.2009. 02364.x

Whiles, M. R., Lips, K. R., Pringle, C. M., Kilham, S. S., Bixby, R. J., Brenes, R., et al. (2006). The effects of amphibian population declines on the structure and function of Neotropical stream ecosystems. Front. Ecol. Environ. 4, 27-34. doi: 10.1890/1540-9295(2006)004[0027:teoapd]2.0.co;2

Wilbur, H. M. (1997). Experimental ecology of food webs: complex systems in temporary ponds. Ecology 78, 2279-2302.

Zanette, L. Y., White, A. F., Allen, M. C., and Clinchy, M. (2011). Perceived predation risk reduces the number of offspring songbirds produce per year. Science 334, 1398-1401. doi: 10.1126/science.12 10908

Conflict of Interest Statement: The authors declare that the research was conducted in the absence of any commercial or financial relationships that could be construed as a potential conflict of interest.

Copyright (c) 2018 Arribas, Touchon and Gomez-Mestre. This is an open-access article distributed under the terms of the Creative Commons Attribution License (CC $B Y)$. The use, distribution or reproduction in other forums is permitted, provided the original author(s) and the copyright owner are credited and that the original publication in this journal is cited, in accordance with accepted academic practice. No use, distribution or reproduction is permitted which does not comply with these terms. 